\title{
Adherence to medical regimen after pediatric liver transplantation: a systematic review and meta-analysis
}

This article was published in the following Dove Medical Press journal: Patient Preference and Adherence

\section{Xingchu Meng \\ Wei Gao \\ Kai Wang \\ Chao Han \\ Wei Zhang \\ Chao Sun}

Department of Organ Transplantation, Tianjin First Center Hospital, Tianjin, China
Correspondence: Wei Gao

Department of Organ Transplantation,

Tianjin First Center Hospital,

No 24 Fukang Road, Nankai District,

Tianjin, 300192, China

Tel +86 I35 02। I I533

Email gaowei_gw2000@163.com
Purpose: Adherence to the medical regimen after pediatric liver transplantation is crucial for good clinical outcomes. However, the existing literature provides inconsistent evidence regarding the prevalence of and risk factors for nonadherence to the medical regimen after pediatric liver transplantation. This study aimed to investigate such nonadherence after pediatric liver transplantation and risk factors associated with this nonadherence using findings of reported studies. Methods: The electronic databases of Excerpta Medica, Ovid Technologies, PubMed and WanFang Data were searched using the keywords "adherence", "liver transplant" and "paediatric". Additionally, relevant references cited in related studies were used to obtain original articles. Using 22 original articles, data regarding nonadherence to the medical regimen after pediatric liver transplantation were quantitatively combined, and risk factors associated with nonadherence were qualitatively identified. Average rates of nonadherence in four areas of medical regimens were calculated. The heterogeneity of the included original articles was also analyzed. When $I^{2}>50$ and $P<0.05$, a random effects model was used; otherwise, a fixed effects model was used. Moreover, Egger's and Begg's tests were used to evaluate publication bias, if any, and original articles with $P>0.05$ were considered to have no publication bias.

Results: The clinical attendance nonadherence rate was 45\% (95\% confidence interval [CI]: 39-51), global nonadherence rate was $17 \%$ (95\% CI: 13-21) and immunosuppression nonadherence rates were 39\% (95\% CI: 26-52) and 34\% (95\% CI: 30-39) for cyclosporine and tacrolimus, respectively. Risk factors included older age of the pediatric patient, low family cohesion, poor social functioning, poor mental health and single-parent family.

Conclusions: The nonadherence rate in pediatric liver transplantation is high. Therefore, intervention on the basis of risk factors, such as mental health and family function, may be necessary. Moreover, a standard technique for assessing nonadherence to the medical regimen after pediatric liver transplantation, comprising as many dimensions as possible, is required in order to be more objective and comprehensive when assessing nonadherence.

Keywords: compliance, transplant, pediatrics, hepar, hepatic

\section{Introduction}

Pediatric liver transplantation is a crucial dimension of clinical liver transplantation. After nearly half a century of development since the first pediatric liver transplantation in $1963,{ }^{1}$ the survival rate has greatly improved. Approximately 30 years ago, pediatric liver transplantation became the standard treatment for infants, children and adolescents suffering from life-threatening, end-stage liver diseases. ${ }^{2}$ Currently, it is one of the most successful solid-organ transplantations with a 5-year survival rate of $>70 \%$ globally. In developed countries, such as the United States and Japan, the proportion of pediatric liver 
transplantation is $>10 \%$ of the total liver transplantation cases, and the 5-year survival rate is approximately $80 \%$, with the living-donor survival rate being even higher. ${ }^{2,3}$ In China, from 1996 to end of 2013, the liver transplantation for children under the age of 18 years registered in the Chinese Liver Transplant Registry (CLTR) is 935 cases, accounting for $3.6 \%$ of the total liver transplants in mainland China. Clinical guidelines for pediatric liver transplantation in China $(2015)^{4}$ also gives detailed clinical guidelines for the diagnosis and treatment for different age-groups, different degree of disease and aspects, etc. Adherence to the medical regimen after liver transplantation is considered critical for avoiding late organ-rejection episodes, graft loss and death, and for decreasing medical costs. ${ }^{5}$ The nonadherence rate to the medical regimen after singlecenter pediatric liver transplantation is as high as $50 \%-70 \%{ }^{6}$ Alternatively, research on risk factors associated with such nonadherence after pediatric liver transplantation is limited.

In this study, we performed a meta-analysis on the nonadherence to the medical regimen after pediatric liver transplantation to retrieve original articles published in any language. The nonadherence rate in four areas of the medical regimen was assessed. Moreover, findings of original articles regarding risk factors associated with nonadherence to the medical regimen after pediatric liver transplantation were investigated.

\section{Materials and methods}

This meta-analysis was conducted and reported in accordance with the Preferred Reporting Items for Systematic Reviews and Meta-Analyses guidelines. ${ }^{7}$

\section{Original article search}

The electronic Excerpta Medica database (EMBASE) Ovid Technologies, PubMed and WanFang Data were searched using the keywords "adherence", "liver transplant" and "paediatric". Moreover, relevant references cited in related studies were used to obtain original articles. Two of the authors separately performed original article search; a third-party expert was consulted in case of disagreement. An attempt was made to retrieve as many original articles as possible, with no limit on the publication language.

\section{Inclusion and exclusion criteria}

Inclusion criteria including: 1) pediatrics liver transplant relevant researchers or patient with age 1-17 years old; ${ }^{8}$ 2) original articles included datum of nonadherence rate; 3) articles provided risk factors of nonadherence of liver post-transplantation.

Exclusion criteria were: 1) patients not children or adolescent; 2) duplicated reports or research or cohort with the same patients; 3) reviews or systematic reviews; 4) case report.

\section{Nonadherence outcomes}

We examined three aspects of nonadherence outcomes: 1) immunosuppression medication nonadherence; 2 ) nonadherence to clinical attendance (patients do not follow doctor's orders to regular clinic appointment and test, reflected from clinical record); 3) "global" nonadherence outcome (original author did not provide a specific nonadherence assessment aspect like immunosuppression or clinical attendance but could reflect nonadherence in multiple, global areas).

\section{Adverse outcomes}

Main adverse outcomes were: 1) rejection; 2) re-transplantation; 3) death.

\section{Information extraction}

We extracted the information of first author, publish year, country, sample age, assessment of nonadherence, sample size, no of nonadherence, duration of observation and study design. If the age-group reported in the original literature was children or adolescents, then we recorded the age-group as the information provided in the original literature. If the original literature did not provide the aforementioned information, we recorded pediatric patients aged $12-17$ as adolescent, others as children. ${ }^{8,9}$

From each original article, information regarding the association of each medical regimen nonadherence outcome with a series of potential risk factors was assessed. The maximum possible number of risk factors hypothesized in the original articles was assessed; these risk factors included i) sociodemographic factors (gender, race/ethnicity, age, family income, parents education status and health insurance) and ii) social psychological factors (single parent or not, mental health of children, family cohesion and social function of children). However, since only a small number of studies examined most of these variables, we could not include these variables in our quantitative analysis.

\section{Article quality assessment}

We used Newcastle-Ottawa scale $(\mathrm{NOS})^{10}$ scale to proceed the quality assessment of retrieved original articles. When NOS scores were lower than five they were regarded as low quality articles and were deleted from our analysis.

\section{Statistical analysis}

Nonadherence rates were combined based on the subgroups. When the sample size from any original article was $<100$, a specific transform fomula ${ }^{11}$ was used to estimate the nonadherence rate and the standard error (SE): 


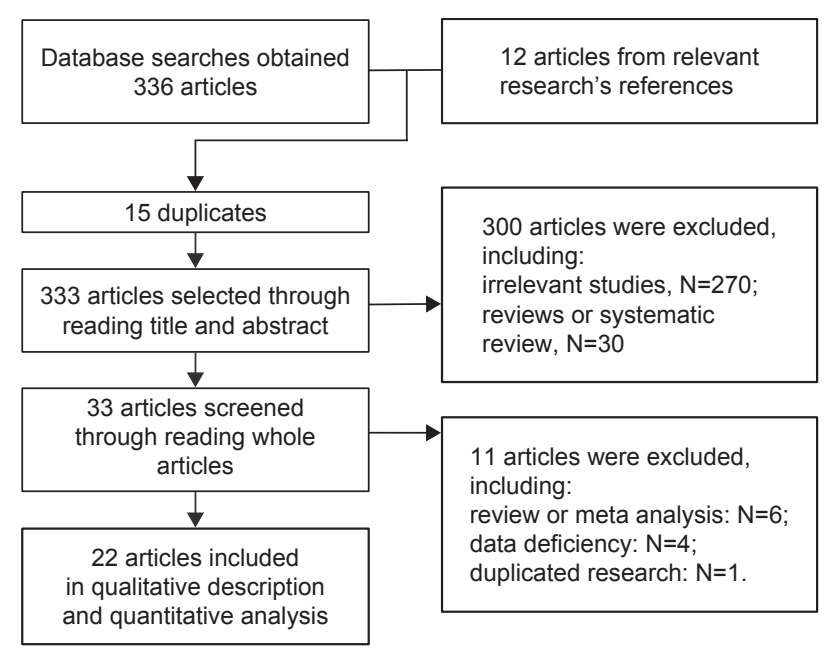

Figure I Meta-analysis article screening flowchart.

$$
\begin{aligned}
\text { TransformedP }= & \operatorname{asin}\{\operatorname{sqrt}[n /(\mathrm{N}+1)]\}+ \\
& \operatorname{asin}\{\operatorname{sqrt}[(n+1) /(\mathrm{N}+1)]\} ;
\end{aligned}
$$$$
\text { SetransformedP }=\operatorname{sqrt}[1 /(\mathrm{N}+1)]
$$

where number of nonadherence $(n)$ is the numerator and number of patients $(N)$ is the denominator.

After the meta-analysis, the summarized estimate and 95\% confidence interval (CI) boundaries were extrapolated back to proportions using the following formula:

$$
\text { AnyProportion }=\left[\sin (\text { AnyTransformedP/2) }]^{2} .\right.
$$

When the original sample size was $\geq 100$ and the provided proportions were not close to 0 or 1 , the provided proportions were used with the following formula:

$$
\mathrm{SE}=\operatorname{sqrt}[P \times(1-P) / N] .
$$

Moreover, the heterogeneity of the original articles was analyzed. When $I^{2}>50$ and $P<0.05$, a random effects model was used to combine the data; otherwise, a fixed effects model was used. ${ }^{12}$ Egger's and Begg's tests were used to evaluate publication bias, if any; $P>0.05$ was

\begin{tabular}{|c|c|c|c|c|c|c|c|c|c|}
\hline First author & Year & Country & Sample age & $\begin{array}{l}\text { Assessment of } \\
\text { nonadherence }\end{array}$ & Patients (n) & & $\begin{array}{l}\text { Duration of } \\
\text { observation } \\
\text { (years) }\end{array}$ & $\begin{array}{l}\text { Study } \\
\text { design }\end{array}$ & $\begin{array}{l}\text { NOS } \\
\text { scores }\end{array}$ \\
\hline Kennard ${ }^{13}$ & |99| & USA & Children & Clinical record & 35 & II & 0.5 & Cohort & 5 \\
\hline Debolt ${ }^{14}$ & 1995 & USA & Children and adolescent & Cyclosporine & 39 & 0 & 4 & Cohort & 5 \\
\hline Sellers ${ }^{15}$ & 1997 & USA & Children and adolescent & Global & 57 & II & 3.7 & Cohort & 6 \\
\hline Sudan ${ }^{16}$ & 1997 & USA & Children and adolescent & Global & 23 & 4 & I & Cohort & 7 \\
\hline Molmenti ${ }^{17}$ & 1999 & USA & Children and adolescent & Cyclosporine & 28 & II & 9 & Cohort & 7 \\
\hline Lurie $^{18}$ & 2000 & USA & Children and adolescent & Global & 19 & 3 & 9 & Cohort & 7 \\
\hline \multirow[t]{2}{*}{ Avitzur' } & 2004 & Canada & Children and adolescent & Global & 32 & 2 & 1.5 & Cohort & 7 \\
\hline & & & Children and adolescent & Cyclosporine & 32 & 8 & 1.5 & Cohort & 7 \\
\hline \multirow[t]{3}{*}{ Berquist $^{19}$} & 2006 & USA & Adolescent & Clinical record & 97 & 37 & 10 & Cohort & 7 \\
\hline & & & Adolescent & Cyclosporine & 27 & 14 & 10 & Cohort & 6 \\
\hline & & & Adolescent & Tacrolimus & 62 & 23 & 10 & Cohort & 7 \\
\hline Annunziato ${ }^{20}$ & 2007 & USA & Adolescent & Global & 14 & 4 & 3 & Cohort & 7 \\
\hline Bueno $^{21}$ & 2007 & Spain & Children & Global & 50 & 5 & 3.3 & Cohort & 8 \\
\hline Fredericks ${ }^{22}$ & 2007 & USA & Children & Clinical record & 38 & 19 & 10 & Cohort & 7 \\
\hline \multirow[t]{3}{*}{ Berquist $^{23}$} & 2008 & USA & Adolescent & Clinical record & 111 & 50 & 5 & Cohort & 6 \\
\hline & & & Adolescent & Cyclosporine & 38 & 21 & 5 & Cohort & 7 \\
\hline & & & Adolescent & Tacrolimus & 73 & 29 & 5 & Cohort & 6 \\
\hline Fredericks ${ }^{24}$ & 2008 & USA & Adolescent & Tacrolimus & 25 & 8 & 2 & Cohort & 7 \\
\hline Shemesh $^{25}$ & 2008 & USA & Children and adolescent & Tacrolimus & 23 & 6 & I & Cohort & 7 \\
\hline Stuber ${ }^{26}$ & 2008 & USA & Children and adolescent & Tacrolimus & 68 & 26 & 2 & Cohort & 7 \\
\hline Venkat $^{27}$ & 2008 & USA & Children & Tacrolimus & 101 & 32 & 5.3 & Cohort & 8 \\
\hline Miloh $^{28}$ & 2009 & USA & Children and adolescent & Clinical record & 41 & 17 & 2 & Cohort & 7 \\
\hline \multirow[t]{3}{*}{ Fredericks ${ }^{29}$} & 2010 & USA & Children and adolescent & Clinical record & 71 & 40 & 9.41 & Cohort & 6 \\
\hline & & & Children and adolescent & Cyclosporine & 71 & 19 & 9.41 & Cohort & 7 \\
\hline & & & Children and adolescent & Tacrolimus & 71 & 22 & 9.41 & Cohort & 5 \\
\hline Bilhartz ${ }^{30}$ & 2015 & USA & Adolescent & Tacrolimus & 48 & 16 & 12 & Cohort & 7 \\
\hline Fredericks ${ }^{31}$ & 2015 & USA & Children and adolescent & Clinical record & 45 & 24 & 1 & Cohort & 7 \\
\hline Bahador $^{32}$ & 2015 & Iran & Children & Global & 112 & 21 & 5 & Cohort & 7 \\
\hline Shemesh $^{33}$ & 2018 & USA & Children and adolescent & Global & 222 & 41 & 10 & Cohort & 7 \\
\hline
\end{tabular}
considered to indicate no publication bias in the original articles.

Table I Characteristic of original studies

Abbreviation: NOS, Newcastle-Ottawa scale. 


\begin{tabular}{|c|c|c|}
\hline Study ID & ES $(95 \% \mathrm{Cl})$ & $\%$ weight \\
\hline $\begin{array}{l}\text { Clinical record } \\
\text { Kennard (1991) }\end{array}$ & $1.19(0.86,1.52)$ & 10.41 \\
\hline Berquist (2006) & $1.33(1.13,1.53)$ & 18.75 \\
\hline Fredericks (2007) & $1.57(1.26,1.88)$ & 11.01 \\
\hline Berquist (2008) & $1.47(1.29,1.66)$ & 19.91 \\
\hline Miloh (2009) & $1.40(1.10,1.70)$ & 11.58 \\
\hline Fredericks (2010) & $1.70(1.47,1.93)$ & 16.05 \\
\hline Fredericks (2015) & $1.64(1.35,1.93)$ & 12.29 \\
\hline Subtotal $\left(I^{2}=41.9 \%, P=0.111\right)$ & $1.48(1.35,1.60)$ & 100 \\
\hline \multicolumn{3}{|l|}{ Global } \\
\hline Sellers (1997) & $0.91(0.65,1.17)$ & 12.27 \\
\hline Sudan (1997) & $0.86(0.46,1.26)$ & 5.50 \\
\hline Lurie (2000) & $0.82(0.38,1.26)$ & 4.63 \\
\hline Avitzur (2004) & $0.51(0.16,0.85)$ & 7.40 \\
\hline Annunziato (2007) & $1.13(0.62,1.63)$ & 3.51 \\
\hline Bueno (2007) & $0.64(0.37,0.92)$ & 10.97 \\
\hline Bahador (2015) & $0.90(0.71,1.08)$ & 21.29 \\
\hline Shemesh (2018) & $0.89(0.76,1.02)$ & 34.44 \\
\hline Subtotal $\left(I^{2}=13.0 \%, P=0.329\right)$ & $0.84(0.74,0.94)$ & 100 \\
\hline \multicolumn{3}{|l|}{ Cyclosporine } \\
\hline Molmenti (1999) & $1.35(0.99,1.72)$ & 18.51 \\
\hline Avitzur (2004) & $1.05(0.71,1.39)$ & 19.34 \\
\hline Berquist (2006) & $1.61(1.24,1.98)$ & 18.28 \\
\hline Berquist (2008) & $1.68(1.36,1.99)$ & 20.37 \\
\hline Fredericks $(2010)$ & $1.09(0.86,1.32)$ & 23.51 \\
\hline Subtotal $\left(I^{2}=70.6 \%, P=0.009\right)$ & $1.34(1.08,1.61)$ & 100 \\
\hline \multicolumn{3}{|l|}{ Tacrolimus } \\
\hline Berquist (2006) & $1.31(1.06,1.56)$ & 13.15 \\
\hline Berquist (2008) & $1.36(1.14,1.59)$ & 15.45 \\
\hline Fredericks (2008) & $1.20(0.82,1.59)$ & 5.43 \\
\hline Shemesh (2008) & $1.07(0.67,1.47)$ & 5.01 \\
\hline Stuber (2008) & $1.33(1.10,1.57)$ & 14.41 \\
\hline Venkat (2008) & $1.20(1.00,1.39)$ & 21.29 \\
\hline Fredericks (2010) & $1.18(0.95,1.41)$ & 15.03 \\
\hline Bilhartz (2015) & $1.23(0.95,1.51)$ & 10.23 \\
\hline Subtotal $\left(I^{2}=0.0 \%, P=0.871\right)$ & $1.25(1.16,1.34)$ & 100 \\
\hline $\begin{array}{c}1 \\
-1.99\end{array}$ & & \\
\hline
\end{tabular}

Figure 2 Summary of meta-analysis regarding to different subgroups.

Note: Weights are from random effects analysis.

Abbreviation: ES, estimated statistics (transformed proportion).

Table 2 Summary of nonadherence rate

\begin{tabular}{|c|c|c|c|c|c|c|}
\hline \multirow[t]{2}{*}{ Nonadherence } & \multirow{2}{*}{$\begin{array}{l}\text { Transformed } \\
\text { proportion }\end{array}$} & \multicolumn{2}{|c|}{ Transformed $95 \% \mathrm{Cl}$} & \multirow{2}{*}{$\begin{array}{l}\text { Estimated } \\
\text { nonadherence } \\
\text { rate (\%) }\end{array}$} & \multicolumn{2}{|l|}{$95 \% \mathrm{Cl}$} \\
\hline & & Lower & Higher & & Lower (\%) & Higher (\%) \\
\hline Clinical & 1.48 & 1.35 & 1.60 & 45 & 39 & 51 \\
\hline Global & 0.84 & 0.74 & 0.94 & 17 & 13 & 21 \\
\hline Cyclosporine & 1.34 & 1.08 & 1.61 & 39 & 26 & 52 \\
\hline Tacrolimus & 1.25 & 1.16 & $\mathrm{I} .34$ & 34 & 30 & 39 \\
\hline
\end{tabular}

Abbreviation: $\mathrm{Cl}$, confidence interval. 


\section{Results}

The EMBASE search and citations of relevant references resulted in 336 and 12 original articles, respectively, of which 15 were excluded as they were duplicates. The final screening of the 333 original articles provided 22 original articles, ${ }^{1,13-33}$ which were categorized into two groups for qualitative and quantitative analyses. Figure 1 shows the flowchart of this selection process. The follow-up period was 6 months to 10 years (Table 1). The clinical attendance nonadherence rate was $45 \%$ (95\% CI: 39-51), global regimen nonadherence rate was $17 \%$ (95\% CI: 13-21) and immunosuppression nonadherence rates were 39\% (95\% CI: 26-52) and 34\% (95\% CI: 30-39) for cyclosporine and tacrolimus (two common immunosuppressors), respectively. Figure 2 provides details regarding the combination result. The way of assessment of nonadherence in methods is various and no standard, thus we did not regroup data into different assessment methods considering the limits of information from original articles. The transform formula was used to proceed with the metaanalysis and to obtain the final combined clinical attendance, global and immunosuppression nonadherence rates (Table 2) and the transformed results will be regarded as our final results. No publication bias was noted among the different subgroups and the overall model (Table 3).

Analysis of all the risk factors associated with nonadherence to medical regimens in pediatric liver transplantation reported in original articles (Table 4) revealed the following five risk factors for poor adherence: older age of the pediatric patient, low family cohesion, poor social functioning, poor mental health, and single-parent family. Evidence from the original articles also suggested that pediatric patients not adhering to the medical regimen are at a higher risk of postliver transplantation rejection, graft loss and death than those with better adherence to the medical regimen.

\section{Discussion}

Nonadherence to the postoperative medical regimen remains a major cause of morbidity and mortality in different clinical settings. ${ }^{18}$ Many studies have reported on the nonadherence of medical regimens after liver transplantation in adults but not too many studies have been reported regarding the same in children and adolescents..$^{25}$ This study is based on a systematic review and meta-analysis of the nonadherence rate in pediatric patients, and it is an investigation and summary of the risk factors associated with nonadherence to provide constructive suggestions for future clinical practice.

Many studies have used immunosuppression levels to define nonadherence to medical regimen after pediatric liver transplantation, with cyclosporine and tacrolimus being the two common immunosuppressors. By combining the provided nonadherence rates associated with cyclosporine and tacrolimus, we found that the immunosuppressor nonadherence rate is around $30 \%$, which is consistent with adult post-liver transplantation immunosuppressors nonadherence and it is a high rate of nonadherence. ${ }^{34}$ The clinical attendance nonadherence rate was found to be much higher than immunosuppression nonadherence rates. The global nonadherence rate was the lowest of the three but still high. Dew et $\mathrm{al}^{5}$ investigated the outcomes of nonadherence to medical regimen in pediatric solid-organ transplantation, including liver transplantation, and their results were consistent with our major findings. Children and adolescents are undergoing psychological and physiological development and because of this they have limited capability of withstanding long-term medication and clinical treatment, and that could be one of the reasons why pediatric post-liver transplantation nonadherence is relatively high. Another possible reason is that the criteria for compliance are not perfect, which could overestimate or underestimate the rate of nonadherence. . $^{34,35}$

For better investigation of the reasons for nonadherence of pediatric post-liver transplantation, we recorded several main risk factors from original articles' information. In this study, risk factors identified for such nonadherence in pediatric liver transplantation were older age of the pediatric patient, low family cohesion, poor social functioning, poor mental health and single-parent family. Despite the above risk factors that we found, Dew et $\mathrm{al}^{5}$ also reported that high parental distress and patients' high distress and low family income were significantly correlated with poorer adherence to medical regimens. During the adolescence period, adolescents begin to have their own independent thought and behavior, but their psychological development is not yet sound and may not produce wholesome health awareness and health beliefs. That may cause older pediatric patients to have a higher nonadherence rate. Studies found that adult patients with low health beliefs, poor mental health, long-term treatment period, poor

Table 3 Summary of publication bias $(P)$

\begin{tabular}{l|l|l|l|l|l}
\hline Publication bias & Global & Clinical record & Tacrolimus & Cyclosporine & Overall \\
\hline Begg's & 0.536 & 0.548 & 0.266 & 0.462 & 0.248 \\
Egger's & 0.55 & 0.989 & 0.423 & 0.348 & 0.419 \\
\hline
\end{tabular}




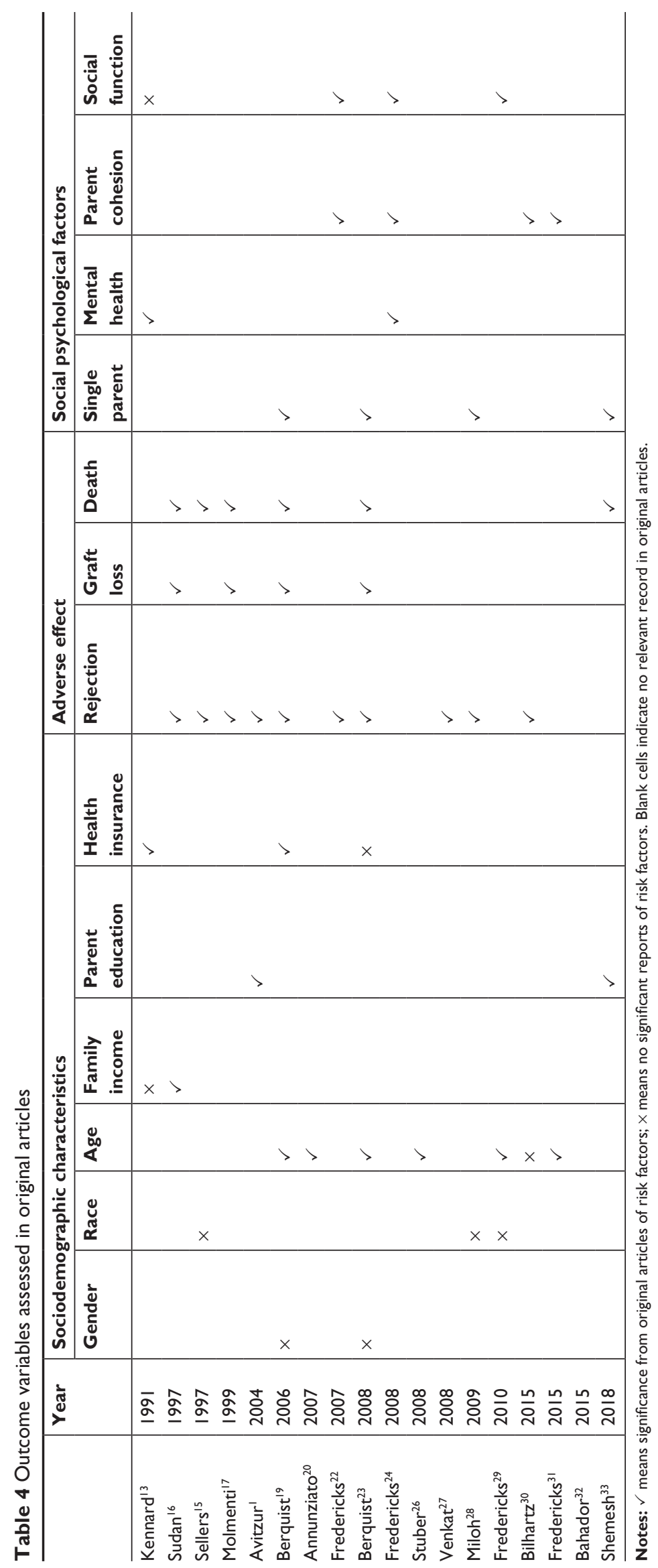


social support and poor socioeconomic status could cause high nonadherence rates among adult organ transplant patients. ${ }^{36,37}$ Differing from adults, pediatric patients' adherence highly relies on their original family. Thus recent studies have tended to investigate the mental health of pediatric patients and family function as risk factors. Fredricks ${ }^{38}$ mentioned that good family function could improve the rate of adherence and quality of life. Annunziato et $\mathrm{al}^{8}$ found that good self-management and psychological health are protective factors for medical regimen nonadherence. Furthermore, a good health care system like good health insurance could decrease parents' financial burden, in other words, lower financial burden can improve patients' adherence in some aspects. ${ }^{39}$

In this study, findings from the original articles indicated that pediatric patients who do not adhere to the medical regimen may have a higher risk of post-liver transplantation rejection, graft loss and death than those who show better adherence to the medical regimen post-liver transplantation. Intervention with respect to the risk factors may improve medical regimen adherence and decrease adverse events. Shemesh et $\mathrm{al}^{25}$ reported that with intervention, the nonadherence rate declined in 2003 and the rate of adverse events reduces compared with that observed without intervention in 1999 and 2000. However, such intervention reports are limited. We suggest that future studies or clinical practice should focus more on the effects of intervention in pediatric patients and their parents during and after pediatric liver transplantation. We found that although studies have mainly focused on medical regimen nonadherence, only a small group of studies researched risk factors associated with nonadherence to medical regimen in pediatric liver transplantation. Thus, we suggest that more study can make efforts to investigate the risk factors toward pediatric nonadherence after liver transplantation.

Our study has several advantages and shortfalls. We quantificationally combined the nonadherence of pediatric patients' nonadherence after liver transplant and qualitatively described the risk factors of this scope through which we provided significant suggestions for clinical practice and research. However, the shortcomings of our study are that we did not regroup data of nonadherence assessment methods because of the limited information from original articles and we did not perform correlation analysis of risk factors and side effects to produce qualitative results of the assessment on how risk factors influence pediatric with liver transplantation. In addition, regarding the risk factors of nonadherence of pediatric post-liver transplantation patients, we can suggest important risk factors but we cannot identify them all.

\section{Conclusion}

The nonadherence rate post-liver transplantation in pediatric patients is high. Therefore, intervention based on risk factors for medical regimen nonadherence, such as mental health and family function, is necessary. In addition, a standard assessment of pediatric medical regimen nonadherence including as many dimensions as possible is required in order to be more objective and comprehensive when assessing nonadherence to medical regimen in pediatric liver transplantation.

\section{Availability of data and material}

All data used for analysis during the current study are displayed in Table 1.

\section{Ethics approval}

Ethical approval was given by the Ethics Committee of Tianjin First Center Hospital, Tianjin, China.

\section{Disclosure}

The authors report no conflicts of interest in this work.

\section{References}

1. Avitzur Y, de Luca E, Cantos M, et al. Health status ten years after pediatric liver transplantation - looking beyond the graft. Transplantation. 2004;78(4):566-573.

2. Ye H, Zhao Q, Wang Y, et al. Outcomes of technical variant liver transplantation versus whole liver transplantation for pediatric patients: a meta-analysis. PLoS One. 2015;10(9):e0138202.

3. Lucianetti A, Guizzetti M, Bertani A, et al. Organ procurement and transplantation liver transplantation in children weighting less than $6 \mathrm{~kg}$ : the Bergamo experience. Transplantation Proc. 2005;37(2):1143-1145.

4. Chinese Society of Organ Transplantation, Chinese Medical Association OTBCMDA. Clinical guidelines for paediatric liver transplantation in China (2015). J Clin Hepatol. 2016;32(7):1235-1244.

5. Dew MA, Dabbs AD, Myaskovsky L, et al. Meta-analysis of medical regimen adherence outcomes in pediatric solid organ transplantation. Transplantation. 2009;88(5):736-746.

6. Bucuvalas JC, Alonso E. Long-term outcomes after liver transplantation in children. Curr Opin Organ Transplant. 2008;13(3):247-251.

7. Liberati A, Altman DG, Tetzlaff J, et al. The PRISMA statement for reporting systematic reviews and meta-analyses of studies that evaluate health care interventions: explanation and elaboration. Ann Intern Med. 2009;151(4):W65-W94.

8. Annunziato RA, Bucuvalas JC, Yin W, et al. Self-management measurement and prediction of clinical outcomes in pediatric transplant. $J$ Pediatr. 2018;193:128-133.

9. Kelly D, Wray J. The adolescent liver transplant patient. Clin Liver Dis. 2014;18(3):613-632.

10. Wells GA, Shea B, O’Connell D, Peterson J, Welch V, Losos M, Tugwell P. The Newcastle-Ottawa Scale (NOS) for assessing the quality of nonrandomised studies in meta-analyses. Ottawa: Ottawa Hospital Research Institute; 2009.

11. Trikalinos T. Meta-analysis of rates. Meta-analysis of rates; 2004. Available from: https://www.stata.com/statalist/archive/2004-09/ msg00386.html. Accessed November 10, 2018. 
12. Sarkhy A, Schreiber RA, Milner RA, Barker CC. Does adjuvant steroid therapy post-Kasai portoenterostomy improve outcome of biliary atresia? Systematic review and meta-analysis. Can J Gastroenterol. 2011;25(8):440-444.

13. Kennard BD, Petrik K, Stewart SM, Waller DA, Andrews WS. Identifying factors in post-operative successful adaptation to pediatric liver transplantation. Soc Work Health Care. 1991;15(2):19-33.

14. Debolt AJ, Stewart SM, Kennard BD, Petrik K, Andrews WS. A survey of psychosocial adaptation in long-term survivors of pediatric liver transplants. Child Health Care. 1995;24(2):79-96.

15. Sellers M, Singer A, Maller E, Olthoff K, Jacobowski D, Shaked A. Incidence of late acute rejection and progression to chronic rejection in pediatric liver recipients. Transplant Proc. 1997;29(1-2):428-429.

16. Sudan DL, Shaw BW, Langnas AN. Causes of late mortality in pediatric liver transplant recipients. Transplant Proc. 1997;29(1-2):430-431.

17. Molmenti E, Mazariegos G, Bueno J, et al. Noncompliance after pediatric liver transplantation. Transplant Proc. 1999;31(1-2):408.

18. Lurie S, Shemesh E, Sheiner PA, et al. Non-adherence in pediatric liver transplant recipients - an assessment of risk factors and natural history. Pediatr Transplant. 2000;4(3):200-206.

19. Berquist RK, Berquist WE, Esquivel CO, Cox KL, Wayman KI, Litt IF. Adolescent non-adherence: prevalence and consequences in liver transplant recipients. Pediatr Transplant. 2006;10(3):304-310.

20. Annunziato RA, Emre S, Shneider B, Barton C, Dugan CA, Shemesh E. Adherence and medical outcomes in pediatric liver transplant recipients who transition to adult services. Pediatr Transplant. 2007;11(6): 608-614.

21. Bueno J, Medina A, Ortega J, et al. Liver transplantation in childhood with more than 10 years of follow-up: analysis of a single-center experience. Transplant Proc. 2007;39(7):2288-2289.

22. Fredericks EM, Lopez MJ, Magee JC, Shieck V, Opipari-Arrigan L. Psychological functioning, nonadherence and health outcomes after pediatric liver transplantation. Am J Transplant. 2007;7(8):1974-1983.

23. Berquist RK, Berquist WE, Esquivel CO, Cox KL, Wayman KI, Litt IF. Non-adherence to post-transplant care: prevalence, risk factors and outcomes in adolescent liver transplant recipients. Pediatr Transplant. 2008;12(2):194-200.

24. Fredericks EM, Magee JC, Opipari-Arrigan L, Shieck V, Well A, Lopez MJ. Adherence and health-related quality of life in adolescent liver transplant recipients. Pediatr Transplant. 2008;12(3):289-299.

25. Shemesh E, Annunziato RA, Shneider BL, et al. Improving adherence to medications in pediatric liver transplant recipients. Pediatr Transplant. 2008;12(3):316-323.
26. Stuber ML, Shemesh E, Seacord D, Washington J, Hellemann G, McDiarmid S. Evaluating non-adherence to immunosuppressant medications in pediatric liver transplant recipients. Pediatr Transplant. 2008;12(3):284-288.

27. Venkat VL, Nick TG, Wang Y, Bucuvalas JC. An objective measure to identify pediatric liver transplant recipients at risk for late allograft rejection related to non-adherence. Pediatr Transplant. 2008;12(1):67-72.

28. Miloh T, Annunziato R, Arnon R, et al. Improved adherence and outcomes for pediatric liver transplant recipients by using text messaging. Pediatrics. 2009;124(5):e844-e850.

29. Fredericks EM, Dore-Stites D, Well A, et al. Assessment of transition readiness skills and adherence in pediatric liver transplant recipients. Pediatr Transplant. 2010;14(8):944-953.

30. Bilhartz JL, Lopez MJ, Magee JC, Shieck VL, Eder SJ, Fredericks EM. Assessing allocation of responsibility for health management in pediatric liver transplant recipients. Pediatr Transplant. 2015;19(5):538-546.

31. Fredericks EM, Magee JC, Eder SJ, et al. Quality improvement targeting adherence during the transition from a pediatric to adult liver transplant clinic. J Clin Psychol Med Settings. 2015;22(2-3):150-159.

32. Bahador Z, Dehghani SM, Bahador A, et al. Parents' education level and mortality and morbidity of children after liver transplantation. Int J Organ Transplant Med. 2015;6(1):25-29.

33. Shemesh E, Duncan S, Anand R, et al. Trajectory of adherence behavior in pediatric and adolescent liver transplant recipients: The medication adherence in children who had a liver transplant cohort. Liver Transpl. 2018;24(1):80-88.

34. Burra P, Germani G, Gnoato F, et al. Adherence in liver transplant recipients. Liver Transpl. 2011;17(7):760-770.

35. Shellmer DA, Dabbs AD, Dew MA. Medical adherence in pediatric organ transplantation: what are the next steps? Curr Opin Organ Transplant. 2011;16(5):509-514.

36. Chisholm MA. Enhancing transplant patients' adherence to medication therapy. Clin Transplant. 2002;16(1):30-38.

37. Wolff G, Strecker K, Vester U, Latta K, Ehrich JH. Non-compliance following renal transplantation in children and adolescents. Pediatr Nephrol. 1998;12(9):703-708.

38. Fredericks EM. Family roles and routines after pediatric liver transplantation: implications for quality of life and beyond. Pediatr Transplant. 2012;16(7):688-691.

39. Fukuda H, Mizobe M, Haruhisa F. Impact of nonadherence on complication risks and healthcare costs in patients newly-diagnosed with diabetes. Diabetes Res Clin Pract. 2017;123(123):55-62.
Patient Preference and Adherence

\section{Publish your work in this journal}

Patient Preference and Adherence is an international, peer-reviewed, open access journal that focuses on the growing importance of patient preference and adherence throughout the therapeutic continuum. Patient satisfaction, acceptability, quality of life, compliance, persistence and their role in developing new therapeutic modalities and compounds to optimize

\section{Dovepress}

clinical outcomes for existing disease states are major areas of interest for the journal. This journal has been accepted for indexing on PubMed Central. The manuscript management system is completely online and includes a very quick and fair peer-review system, which is all easy to use. Visit http://www. dovepress.com/testimonials.php to read real quotes from published authors. 